\title{
Convalescent Plasma Rescued a Severe COVID-19 Patient with Chronic Myeloid Leukemia Blast Crisis and Myelofibrosis
}

\author{
Ciddi COVID-19 Geçiren, Blast Krizi ve Myelofibrozisi Olan Kronik Myeloid Lösemi \\ Hastasının Immün Plazması ile Etkin Tedavisi
}

\author{
(D) Lu-Lu Zhang1, (D) Yu Liu1, (D) Yi-Gang Guo1, (D) Juan Chang1, (D) Bo Gao², (D) Zhang-Zhi Li1, (D) Wei Geng1, (D) Pin Huㄹ, (D) Bin Song1, \\ (D) Xia Zhang1, (D) Chu-Cheng Wan ${ }^{1}$ \\ ${ }^{1}$ Taihe Hospital Affiliated to Xi'an Jiaotong University Health Science Center, Department of Hematology, Shiyan, China \\ 2 Taihe Hospital Affiliated to Xi'an Jiaotong University Health Science Center, Department of Laboratory Medicine, Shiyan, China
}

\section{To the Editor,}

Coronavirus disease-2019 (COVID-19) is now an unprecedented worldwide pandemic. However, there are no specific antiviral drugs available for its treatment. A handful of studies have summarized convalescent plasma (CP) transfusion in severe or critical cases $[1,2,3,4,5,6]$, whereas therapies for COVID-19 in cases of hematologic cancer are rather limited. We give the first report of the initial clinical experience with $\mathrm{CP}$ transfusion administered to a severe COVID-19 patient with chronic myeloid leukemia blast crisis (CML-BP) and myelofibrosis.

A 46-year-old female patient presented with diarrhea, a cough with clear sputum, and fatigue for 3 days. Her previous history of treatment for CML-BP consisted of daunorubicin at $45 \mathrm{mg} / \mathrm{m}^{2}$ for 3 days and cytarabine at $200 \mathrm{mg} / \mathrm{m}^{2}$ for 7 days in a continuous infusion, and then she experienced discontinuation of the tyrosine kinase inhibitor therapy. She was given imatinib (600 mg/day) starting in November 2017, but a drug-related hematologic adverse event occurred quickly. As a result, dasatinib (150 mg/day) was given instead. She had not achieved complete hematological remission at the diagnosis of COVID-19 due to poor responses to these therapies. At admission (February 21, 2020), the most relevant clinical findings included white blood cell count of $4.93 \times 109 / \mathrm{L}$ with 78\% neutrophils, 9.2\% lymphocytes, $2.3 \%$ basophils, $0.4 \%$ eosinophils, and $10.1 \%$ monocytes; hemoglobin of $51 \mathrm{~g} / \mathrm{L}_{\text {; }}$ platelet count of $79 \times 109 / \mathrm{L}_{\text {; }}$ high-sensitivity C-reactive protein of $57.43 \mathrm{mg} / \mathrm{L}$; and interleukin-6 level of $59.25 \mathrm{pg} / \mathrm{mL}$. The real-time polymerase chain reaction (RT-PCR) assay of the throat swab was positive for severe acute respiratory syndrome-coronavirus-2 (SARS-CoV-2) infection. A chest CT obtained on February 21 revealed bilateral ground-glass opacities primarily distributed along the pleura (Figures 1a and 1d). Bone marrow examination and flow cytometry suggested a blast crisis, with 20.5\% of leukemic blasts (Figure 2a) that expressed CD33 and CD13 and partially CD41, CD34, HLA-DR, and cMPO (Figure 2c). RT-PCR revealed a major chimeric $B C R-A B L 1$ transcript. Fluorescence in situ hybridization analysis confirmed the BCR-ABL1 fusion rearrangement signal. Gene sequencing showed no mutation in the ABL1 kinase domain. Cytogenetics were characterized as $46, \mathrm{XX}, \mathrm{t}(3 ; 17)(\mathrm{q} 21 ; \mathrm{q} 21), \mathrm{t}(9 ; 22)(\mathrm{q} 34 ; \mathrm{q} 11)$ [19]/47,idem, +8 [1] (Figure 2d). A biopsy specimen detected grade 2 fibrosis (Figure 2b) according to the marrow fibrosis scoring system. Computed tomography (CT) scanning showed hepatosplenomegaly $(21 \mathrm{~cm}$ in length). The disease was consistent with COVID-19 and CML-BP with myelofibrosis.

The patient developed worsening hypoxemia, with oxyhemoglobin saturation $\left(\mathrm{SaO}_{2}\right)$ oscillating between $90 \%$ and $93 \%$, after receiving conventional antiviral therapy including arbidol (200 mg three times daily), oseltamivir (75 mg twice daily), ribavirin (500 mg every 12 hours), and interferon-alpha- $2 b$ inhalation (5 million units twice daily). A follow-up chest CT scan showed increased consolidation and extended opacities (Figures $1 \mathrm{~b}$ and 1e). On February 26, the patient received a transfusion of $200 \mathrm{~mL}$ of CP obtained from a donor who had recovered from SARS-CoV-2 infection in January 2020 with the neutralizing antibody titer above 1:640. No immediate adverse reactions were observed after plasma infusion. One day later, her $\mathrm{SaO}_{2}$ increased to $98 \%$ with oxygenation index of $200 \mathrm{mmHg}$. At the same time, her clinical symptoms and pathological criteria improved rapidly within 3 days. The patient's condition improved to stable; thus, treatment with pulsed dasatinib was administered (100 mg once daily). Three repetitive RT-PCR tests were negative from the $6^{\text {th }}$ to $8^{\text {th }}$ day after CP transfusion. Chest images showed absorption of opacities within 10 days (Figures $1 \mathrm{c}$ and $1 \mathrm{f})$. The patient recovered and was discharged on the $14^{\text {th }}$ day of admission. 
A recent study showed a 10\% case rate of COVID-19 among 128 patients with hematological cancers in Wuhan [7]. The treatment of severe COVID-19 has been challenging. This pilot study on CP therapy shows that it can serve as a promising rescue option for hematologic cancer patients with severe COVID-19, which warrants further investigation by randomized trials.
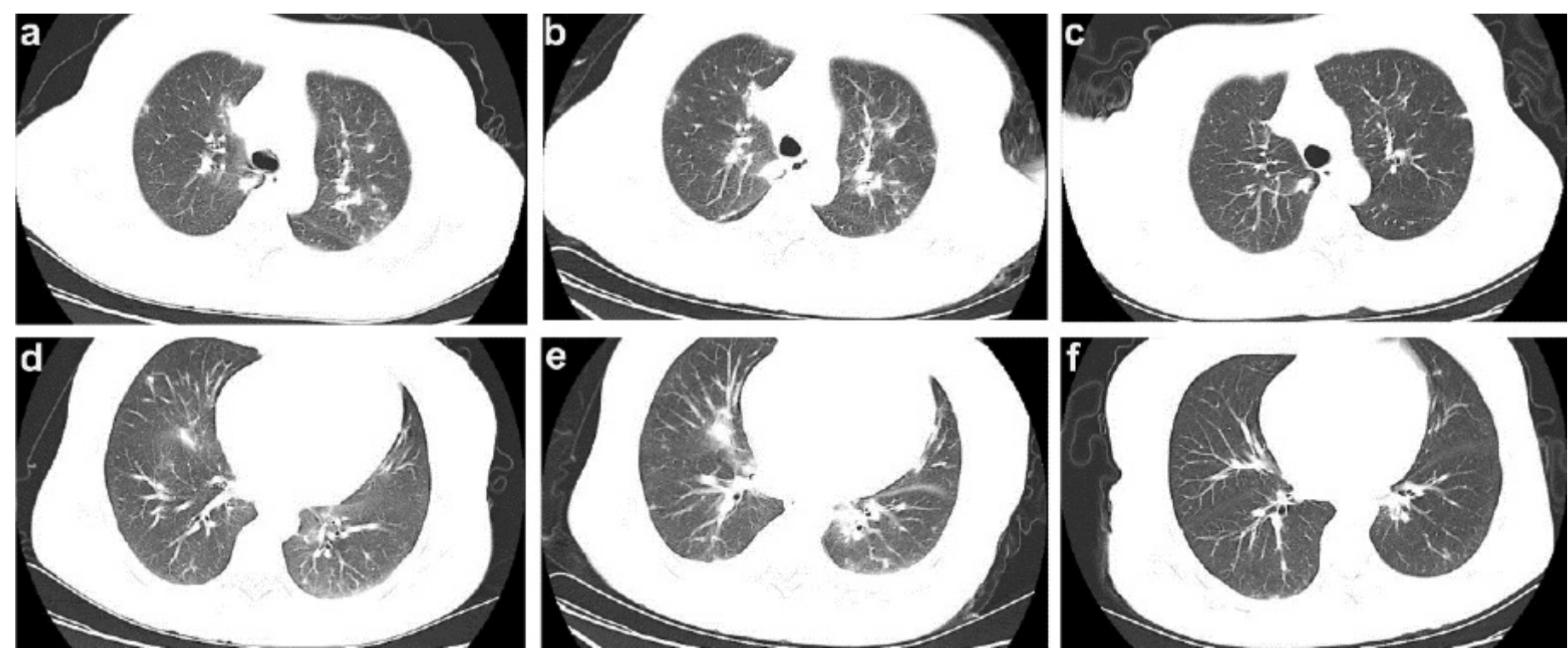

Figure 1. Representative chest computed tomography (CT) scans of this patient. a, d) Chest CT scan obtained at admission showed multiple ground-glass opacities with uneven density involving both upper lungs and right lung. b, e) Chest CT obtained on February 25 before $\mathrm{CP}$ transfusion, where multiple shadows of high density in both upper lungs and patchy consolidation in the right lung were observed. c, f) CT image taken on March 6 showed the absorption of bilateral ground-glass opacity after CP transfusion.
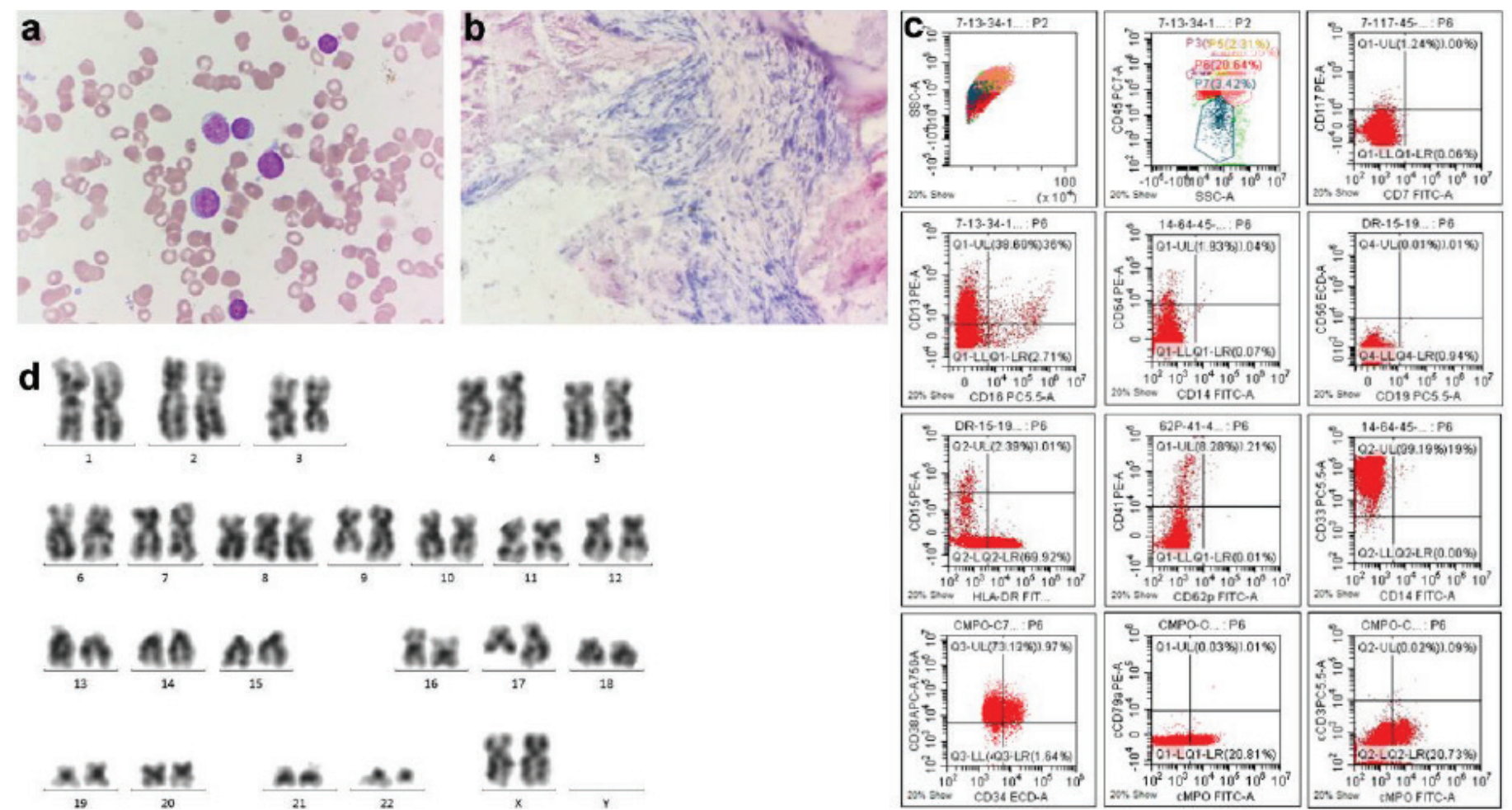

Figure 2. Morphology, flow cytometry, and cytogenetics of the patient at admission. a) Bone marrow aspirate smear (Wright-Giemsa stain, original magnification 1000x) showed leukemic blast cells. b) Bone marrow biopsy (H\&E stain, original magnification 100x) showed fibrosis. c) Flow cytometry plots showed a single cluster of blasts with positivity for CD33 and CD13 and partial CD41, CD34, HLA-DR, and cMPO. d) Karyotype of bone marrow showed $t(9 ; 22)$ and $t(3 ; 17)$ abnormality in the same leukemic clone cells. 
Keywords: COVID-19, Chronic myeloid leukemia, Blast crisis, Convalescent plasma therapy

Anahtar Sözcükler: COVID-19, Kronik myeloid lösemi, Blast krizi, Nekahat plazma tedavisi

\section{Ethics}

Informed Consent: It was received.

Conflict of Interest: The authors of this paper have no conflicts of interest, including specific financial interests, relationships, and/or affiliations relevant to the subject matter or materials included.

Financial Disclosure: This work was supported by the National Natural Science Foundation of China under Grant (81900141) and the Natural Science Foundation of Hubei Province under Grant (2018CFB174).

\section{Authorship Contributions}

Design: L-L.Z., C-C.W.; Data Collection or Processing:Y. L., Y-G.G., J.C., B.G.; Analyses: Z-Z.L., W.G., P.H.; Literature Search: B.S., X.Z.; Writing: L-L.Z.

\section{References}

1. Duan K, Liu B, Li C, Zhang H, Yu T, Qu J, Zhou M, Chen L, Meng S, Hu Y, Peng C, Yuan M, Huang J, Wang Z, Yu J, Gao X, Wang D, Yu X, Li L, Zhang J, Wu
$X$, Li B, Xu Y, Chen W, Peng Y, Hu Y, Lin L, Liu X, Huang $S$, Zhou Z, Zhang L, Wang $Y$, Zhang Z, Deng $K$, Xia Z, Gong $Q$, Zhang W, Zheng X, Liu Y, Yang $H$, Zhou D, Yu D, Hou J, Shi Z, Chen S, Chen Z, Zhang X, Yang X. Effectiveness of convalescent plasma therapy in severe COVID-19 patients. Proc Natl Acad Sci U S A 2020;117:9490-9496.

2. Bradfute $S B$, Hurwitz I, Yingling $A V$, Ye $C$, Cheng $Q$, Noonan TP, Raval JS, Sosa NR, Mertz GJ, Perkins DJ, Harkins MS. Severe acute respiratory syndrome coronavirus 2 neutralizing antibody titers in convalescent plasma and recipients in New Mexico: an open treatment study in patients with coronavirus disease 2019. J Infect Dis 2020;222:1620-1628.

3. Bloch EM, Shoham S, Casadevall A, Sachais BS, Shaz B, Winters JL, van Buskirk C, Grossman BJ, Joyner M, Henderson JP, Pekosz A, Lau B, Wesolowski A, Katz L, Shan H, Auwaerter PG, Thomas D, Sullivan DJ, Paneth N, Gehrie E, Spitalnik S, Hod EA, Pollack L, Nicholson WT, Pirofski LA, Bailey JA, Tobian AA. Deployment of convalescent plasma for the prevention and treatment of COVID-19. J Clin Invest 2020;130:2757-2765.

4. Zhang B, Liu S, Tan T, Huang W, Dong Y, Chen L, Chen Q, Zhang L, Zhong Q, Zhang X, Zou Y, Zhang S. Treatment with convalescent plasma for critically ill patients with severe acute respiratory syndrome coronavirus 2 infection. Chest 2020;158:e9-e13.

5. Xia X, Li K, Wu L, Wang Z, Zhu M, Huang B, Li J, Wang Z, Wu W, Wu M, Li W, Li L, Cai Y, Bosco B, Zhong A, Liu X, Lv T, Gan Z, Chen G, Pan Y, Liu C, Zhang $K_{1}, X_{X}$, Wang $C$, Wang 0 . Improved clinical symptoms and mortality among patients with severe or critical COVID-19 after convalescent plasma transfusion. Blood 2020;136:755-759.

6. Chen L, Xiong J, Bao L, Shi Y. Convalescent plasma as a potential therapy for COVID-19. Lancet Infect Dis 2020;20:398-400.

7. He W, Chen L, Chen L, Yuan G, Fang Y, Chen W, Wu D, Liang B, Lu X, Ma Y, Li L, Wang H, Chen Z, Li Q, Gale RP. COVID-19 in persons with haematological cancers. Leukemia 2020;34:1637-1645. 